\title{
Development of Decision-Making Algorithms Based on Irreversiblemathematical Calculations in the Assessment of Students' Knowledge
}

\section{Seytnazarov Kuanishbay Kenesbaevich,}

Doctor of technical Sciences of the Nukus branch Tashkent University of Information Technology named after Muhammad Al-Khorezmi, Nukus, Uzbekistan, seytnazarov82tuitnf@gmail.com

Kalimbetov Kamal Ilolovich, Assistant teacher of mathematics teaching methods of Nukus State Pedagogical Institute named after Ajiniyaz, Nukus, Uzbekistan, kamu_8787@mail.ru

\section{Annotation}

In order to improve the quality of education, it is necessary to update the system of student assessment, that is, to develop personality, broaden the imagination, enrich thinking and create a system of assessment management in the subject, based on solid mathematical methods.

The article develops an algorithm for solving the problem of taking students to the new stage of the assessment process, that is, the algorithm of the assessment system.

Keywords: Pedagogy, quality of education, assessment,uninterrupted mathematical modeling, algorithm, relevance function

Introduction: Problem-based learning is based on the problem (Greek "obstacle", "difficulty") or problem situation, and problembased learning technology serves to find their solution. In many cases, problem and problematic situation are taken as synonyms. In fact, they are different from each other

Problem (Greek "obstacle", "difficulty", Arabic "mystery",

"Mysterious", "difficult to understand") - it is important to solve

an issue of theoretical and practical significance

In essence, the problem is solved on the basis of studying the causes of it, looking for important, effective ways, methods and means to solve it, gathering evidence to prove their effectiveness, interpreting the evidence in a new, new way.

In the field of pedagogy, the concept of "problem" is often used to address organizational, pedagogical, psychological, educational and pedagogical issues. From the point of view of the field in the pedagogical process the following problems are addressed:

- didactic problem;

- practical problem;

- scientific and methodological problem;

- A problem of a purely scientific nature 
The structure of the assessment system: Known knowledge, unknown knowledge and existing experience are manifested as components of the problem. With this in mind, we have developed a method that focuses the student's attention on specific factors in the use of the method in the classroom, as well as a management system of assessment in the subject, which develops, broadens the imagination, enriches thinking and conducts student assessment.

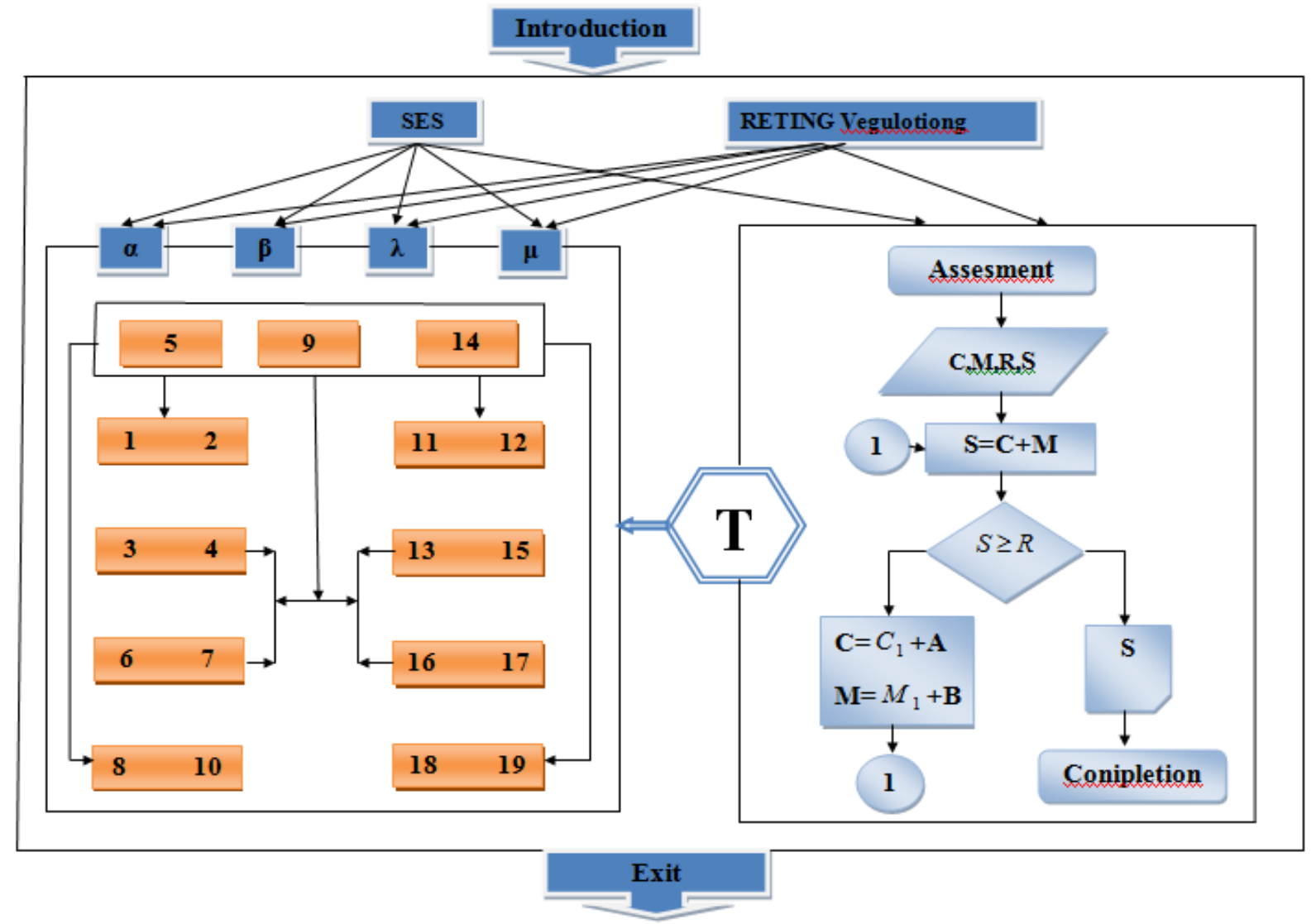

Figure 1 Evaluation control system algorithm

In this

$\lambda$-Opportunities, $\beta$-Students, $\alpha$-Objects, $\quad \mu$ Subjects

C-Students earn points from the continuous assessment (CA)

M-Students score from midcourse assessment (MA)

S- Students' scores from continuous assessment(CA) and midcourse assessment (MA)

R-Criteria for assessing students' knowledge based on a rating system

A-An indicator of additional mastery for the continuous assessment, depending on the features of the subject transferring index

B- An indicator of additional mastery for midcourse assessment, depending on the features of the subject and additional transferring index 1,2,3,..., 19- Students, T-Teacher.

The issue of assessing learner's mastery is a multi-criteria and difficult to formulate on the basis of parts of the initial data. The use of a statistical method in assessment often presents some problems. For example, the statistical evaluation method is characterized by the difficulty of creating the necessary conditions for conducting a large number of non-interactive experiments on the observed process or parameter. Such information includes information on the student's mastery and linguistic assessment of attendance, as well as information on his 
psychology. An effective method of processing arbitrary types of data, especially data in a fixed form, is the method of fixed sets.

\section{MATHEMATICAL SOLUTIONS IN ASSESSMENT}

The use of inflexible logic allows the problem to be solved successfully in weakly formed initial data.In addition, the development and implementation of rules close to natural language significantly increases the degree of approximation to the required results of the conclusion. The following form should be considered when introducing a variety of assessments of the knowledge, skills and experience acquired by learners in the achievement of educational performance. There are some points are given to achieve high indication in the process educational system.

We assume that $X$ the value of the level of each $x$ element of the domain of $A_{2}$ definition corresponds to that set given $[0 ; 1]$ for this interval and assume that the value of the level corresponding to this set given by the following relevance function corresponds to, $\mu_{A_{2}}(x)$

$$
\mu_{A_{2}}(x): X \rightarrow[0 ; 1]
$$

In that case $A_{2}$ set is the second indefinite set.

Example assessment set, $X=\{$ unsatisfactory, normal, satisfactory $\}=\left\{x_{1}, x_{2}\right.$, element)

$L=\{$ low, average, high $\}=\left\{l_{1}, l_{2}, l_{3}\right\}$

" $\{$ send, stop $\}$ " set of indefinite levels, $A_{2}$

“ $\{$ send, stop $\} "$ set:

$A_{2}=\left\{\frac{\text { low }}{\text { unsatisfactory }}, \frac{\text { avarage }}{\text { normal }}, \frac{\text { high }}{\text { satisfactory }}\right\}\left\{\frac{l_{1}}{x_{3}}, \frac{l_{2}}{x_{2}}, \frac{l_{3}}{x_{1}}\right\}$

Demonstration of an uncertain degree of belonging to the evaluation set can be as shown in Figure 1.
The set " $\{$ send, stop $\}$ " can be represented graphically in accordance with Figure 1.

Assessing the status of the release or termination of a mineral set is usually based on the degree to which a particular " $\{$ send, stop $\}$ " set level belongs, e.g.

$$
\mu_{A_{2}}(\text { stop })=0,99
$$

it is difficult to determine the shape.

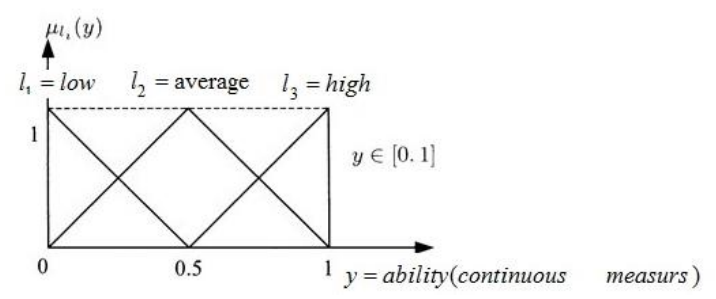

Figure 1. $\mu_{l_{i}}$ demonstration of the membership function to a set " $\{$ send, stop $\}$ " of an indefinite degree of membership

The only best way to assess the relevance in this case is to rate it indefinitely using the values high, average, and low.

$$
\mu_{A_{2}}(x) \text { degree of belonging } A_{2} \text { if the }
$$

degree of relevance is given to an indefinite set using indefinite sets (they are also indefinite sets), then the second type is called an indefinite set. The second type is an example of a set of pairs of undefined sets (2):

( $x$ elements $A_{2}$ set belongs indefinite degree $x$

from a set of the first type:

$A_{2}=\left\{\left(\mu_{A_{2}}^{*}(x), x\right)\right\}, \forall x \in X$. 

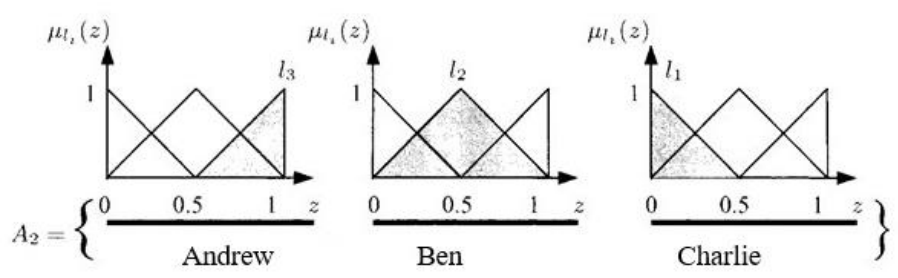

Figure 2. Graphical representation of the set " $\{$ send, stop $\}$ " where, is $\mu_{A_{2}}^{*}(x)-x$ element's

$A$ the degree to which the element belongs to the set, $\mu_{A_{2}}(x)$ function is given as follows:

$$
\mu_{A_{2}}(x): X \rightarrow L,
$$

where, $X \quad A_{2}$ the domain of the set is $L=\left\{l_{1}, l_{2}, \ldots, l_{m}\right\} \quad A_{2}$ the uncertainty of the degree of relevance of the set $\left\{\left(\mu_{l_{i}}^{*}(y), y\right)\right\}$ $A_{2}$ to the set of

$l_{i}$ indeterminate values $A_{2}$ the function of belonging to $\mathrm{Y}$ a set of indeterminate degrees of belonging he area of determination of the uncertain degree of belonging $y: y \in \mathrm{Y}$

The first type of affiliation function set depends on $x \in \mathrm{X}$ one variable, so the second type affiliation function set is a function of two variables as follows;

$$
\mu_{A_{2}}(x, y): X \rightarrow L, Y \rightarrow L \text {. }
$$

This is effective not only in the educational process, but also in other areas. Assessment of the knowledge, skills and experience of the learners assessment through the rating rules encourages the person to think freely, creatively and non-standardly.

\section{CONCLUSION}

In conclusion, the article discusses the issues of improving the quality of education, the development of students and the assessment of students by teachers, especially in the field of specific disciplines, the solution of shortcomings of traditional methods in the assessment of new mathematical methods. One of the new directions in the field of mathematics is the ways and algorithms for finding solutions using nonrigorous mathematical methods:

- Problem situations in the development of the assessment system, that is the improvement of the process of accurate presentation of students' knowledge were mentioned.

- A student assessment system has been developed to broaden the individual's mind, enrich their thinking, and provide an assessment of the academic subject in which the lesson is taught.

- Algorithms for finding accurate solutions based on non-rigorous mathematical methods to assess the knowledge, diary and experience of students in increasing the rate of education, that is, to bring accuracy using numerical processing of inaccurate data in a large number of data.

\section{References}

1. Asian Journal of Multidimensional Research ISSN (Online): 2278-4853 https://tarj.in/images/download/ajmr/AJMRMARCH-2020-FULL-JOURNAL.pdf

2. European Journal of Research and Reflection in Educational Sciences. Vol.8 No.3,2020 ISSN 2056-5852 http://www.idpublications.org/wpcontent/uploads/2020/03/Full-Paper-USING-ETEXTBOOKS-FOR-TEACHING-COMPUTERGRAPHICS- AND-GLOBALIZING-IT-1.pdf

3. International Journal of Psychosocial Rehabilitation ISSN: 1475-7192 https://www.psychosocial.com/article/PR201295/ 12148/

4. International Journal of Academic Research in Business, Arts \& Science IJARBAS 
https://www.ijarbas.com/2020/03/10/quality-of-

the-problem-lesson-its-goals-and-objectives/

5. Aho E. Creating an Innovative Europe: http://ec.europa.eu/invest-in research / pdf / download_en / aho_report.pdf.

6. Pegat A. Fuzzy modeling and control (Moscow 2013)

7. Solodovnikov I. V., Rogozin O. V., Shuruev O. V., Expert system for evaluating the effectiveness of training based on the mathematical apparatus of fuzzy logic, Quality control of the educational process, No. 1, 2006, 19-22 p.

8. Garry G. Azgaldov Alexander V. Kostin Alvaro E. Padilla OmisteThe ABC of Qualimetry Fonts kindly provided by ParaTypeIncRedero 2015. 